\title{
Gas6 expression and Tyrosine kinase AxI Sky receptors: Their relation with tumor stage and grade in patients with bladder cancer
}

\author{
Murat Akgül ${ }^{1}$, Özgür Baykan ${ }^{2}$, Zeynep Çağman ${ }^{3}$, Mustafa Özyürek ${ }^{4}$, Illker Tinay ${ }^{5}$, Cem Akbal $^{6}$, \\ Fikriye Uras ${ }^{7}$, Levent Türkeri ${ }^{6}$ \\ ${ }^{1}$ Department of Urology, Tekirdag Namık Kemal University Medical School, Tekirdağ, Turkey; \\ ${ }^{2}$ Department of Biochemistry, Balıkesir University Medical School, Balıkesir, Turkey; \\ ${ }^{3}$ Department of Biochemistry, Bezmialem University, School of Pharmacy, Istanbul, Turkey; \\ ${ }^{4}$ Department of Physiology, Marmara University, School of Medicine, Istanbul, Turkey; \\ ${ }^{5}$ Anadolu Medical Center, Gebze, Kocaeli,Turkey; \\ ${ }^{6}$ Department of Urology, Acibadem University, School of Medicine, Istanbul, Turkey; \\ ${ }^{7}$ Department of Biochemistry, Marmara University, School of Pharmacy, Istanbul, Turkey.
}

\begin{abstract}
Summary Objectives: It has been shown that the dysregulation of tyrosine kinase Axl receptor and its ligand growth arrest-specific gene (Gas6) are associated with poor prognosis in various types of tumors but there is not enough study about their importance in bladder cancer (BC). We evaluated the relation of Gas6 gene expression and tyrosine-kinase Axl and Sky (Tyro 3) receptors with tumor stage and grade in patients with $B C$.

Material and Methods: The study group consists of 55 patients whose transurethral resection of bladder (TUR-B) has been performed due to $B C$ and the control group consists of 12 patients with normal bladder mucosa. In tissues mRNAs of Gas6, Axl, and Sky receptors were examined by quantitative (Real-Time) PCR (qPCR). Protein expression was measured by immunohistochemistry. Plasma Gas6 protein levels were compared with control group by ELISA method.

Results: Patients with BC were grouped as Ta low $(n=17)$, Ta high $(n=5)$, T1 low $(n=9)$, T1 high $(n=8)$ and T2 $(n=16)$ according to their TUR-B pathologies. The qPCR analysis showed that the expression of Gas6 gene and Axl receptor is higher in the tumor-positive group and the immune-histochemical showed that the bladder samples of the tumor-positive group stained significantly positive. When the patients are grouped according to the TUR-B pathologies, a statistical significant difference was observed among groups in the qPCR analysis ratios of Gas6 gene and Axl receptor by $(p<0.05)$ but no significance was found for Sky receptor $(p>0.05)$. When Gas6 protein levels in plasma samples were compared by ELISA method, a statistical significance was determined among groups $(p=0.001)$.

Conclusions: Our findings indicate that mRNAs of Gas6 and Axl receptor are closely related to tumor stage and grade in patients with BC. Further studies are needed for understanding the role of Gas6 and its receptors on the neoplastic transformation in terms of novel biomarkers and potential therapeutic targets.
\end{abstract}

KEY WORDS: Bladder cancer; Gas6; Axl; Sky; Tyro3.

Submitted 31 March 2021; Accepted 17 May 2021

\section{INTRODUCTION}

According to the GLOBOCAN data, bladder cancer (BC) is the $7^{\text {th }}$ most commonly diagnosed cancer in men and it declines to 11th worldwide, when both sexes are considered (1). Worldwide age-standardized mortality rate has been reported as 3.2 for men vs. 0.9 for women per 100.000 persons, however incidence and mortality rates vary depending on the healthcare systems, management protocols and development level of the countries.

The most common subtype of $\mathrm{BC}$ is urothelial carcinoma (UC) and the molecular mechanism of UC is not completely understood as in other cancers (2).

Receptor tyrosine kinases (RTKs) play key roles in cellular signal transduction and they are one of the most common types of molecules investigated for this purpose. In humans, 20 distinct subfamilies of RTKs exist that are categorized according to their aminoacid sequence identities and structural similarities in their extracellular regions (3). One of these is the subfamily of TAM receptors comprising Sky (Tyro3), Axl, and Mer. They participate in a signaling axis where growth arrest-specific 6 (Gas6) protein is a ligand (4). The oncogenic nature of Axl, Sky and Mer is demonstrated through activation of signaling pathways involved in proliferation, migration, invasion, angiogenesis, inhibition of apoptosis, and therapeutic resistance (5). It has been shown that overexpression of Axl, Sky, Mer RTKs, and their ligand Gas6 is associated with poor prognosis in various types of tumors (6). The close relationship with the pathogenesis of many cancers suggests that Gas6 and its TAM receptors could be potential biomarkers and targets for treatment (7).

The molecular biology of BC is complex and not fully understood. There is a very limited number of studies investigating the relationship between $B C$ and Gas6/TAM receptors. Yeh et al. investigated the role of Axl in the pathogenesis of locally advanced and metastatic BC patients (8). They indicated that c-Met and its crosstalk with Axl could contribute to the progression of 
human BC. Rui et al. investigated the relationship between long noncoding RNA and BC (9). They showed that GAS6-AS2, a long noncoding RNA, was significantly up-regulated in BC tissues and positively correlated with tumour stages and poor prognosis. Identification of new prognostic markers and therapeutic targets for $B C$ is urgently required. In the present study, we aimed to elucidate the relation between Axl/Sky/Mer RTKs and its ligand Gas6 in patients with UC of bladder.

\section{MATERIALS AND METHODS}

The sample size was calculated based on the formula according to the previously published studies $(6,8)$. Our study group includes 55 patients with transurethral resection of bladder tumor, where the histopathological diagnosis of the tumors was UC. The control group consists of the 12 patients whom bladder mucosa has been biopsied during radical prostatectomy operation. Tissues from bladder tumor or mucosa were stored at $-80^{\circ} \mathrm{C}$.

In this study, mRNA expression of Axl, Sky, and Gas6 in the tissues was analyzed by quantitative (real-time) polymerase chain reaction (qPCR). Protein expression of Gas6, Axl, and Sky was analyzed by immunohistochemistry.

Plasma and urine samples of patients were collected before transurethral resection and Enzyme linked Immunosorbent Assay (ELISA) was used to measure Gas6 protein level. Plasma and urine samples of a control group, who are older than 40 years of age and without any history of malignancy, has been used for comparison. The urine and venous plasma aliquots were stored at $-80^{\circ} \mathrm{C}$ before analysis after centrifugation at $2300 \mathrm{~g}$ for 15 min at room temperature.

The study has been approved by the local institutional ethics committee (Approval number: 09.2012.0087) and conducted in conformity with the Declaration of Helsinki in 1995. Written informed consent were obtained from all patients included in the study.

\section{Real-time PCR ( $q P C R$ )}

Total RNA was isolated using TriPure isolation reagent solution (Roche, Mannheim, Germany) according to the manufacturer's instructions. The mRNA expression of the Gas6, Axl and Sky were determined using specific primer sequences.

Specific primer sequences used for the Gas6 gene:

- 5'-TGCTGTCATGAAAATCGCGG-3' (gas6-5'; 13281347)

- 5' CAtgtagtCCAGGCTGTAGA-3' (gas6-3'; 15941613)

Specific primer sequences used for the Axl receptor gene:

- 5'-GGTGGCTGTGAAGACGATGA-3' (Axl-5'; 18201839)

- 5' CTCAGATACTCCATGCCACT-3' (Axl-3'; 21032122)

Specific primer sequences used for the Sky receptor gene:

- 5'-CACTGAGCTGGCTGACTAAGCCCC-3'(Sky-5'; 2719-2742)

- 5'-AATGCATGCACTTAAGCAGCAGGG-3'(Sky-3'; 3039-3062)
Figure 1.

The cytoplasmic staining of immune expression for Gas6 protein and Axl, Sky receptors proteins positivity in BC tissue. According to the intensity of staining, it was scored as 1A: 0, 1B: +1, 1C: +2, 1D: +3.

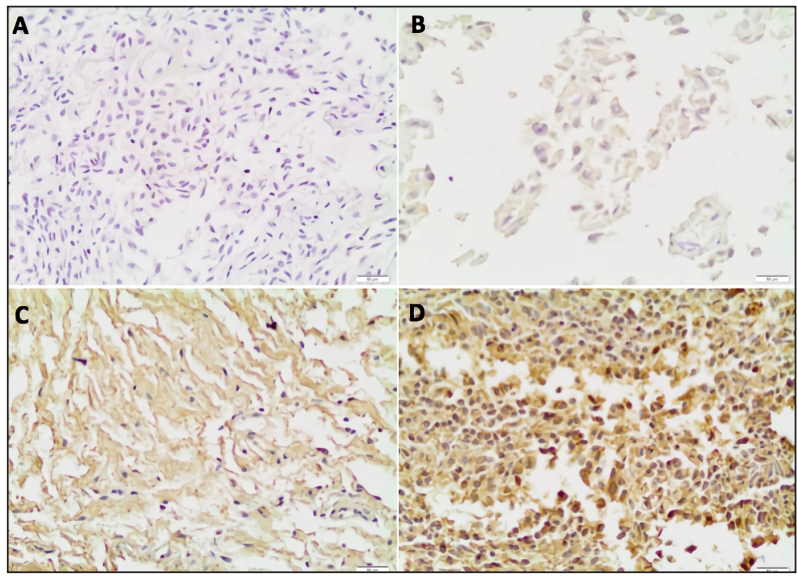

The qPCR analysis was performed using SYBR Green dye (Light Cycler-RNA Amplification Kit SYBR Green I; Roche, Mannheim, Germany). Target gene expression was determined by comparing the amount of threshold loop with the glyceraldehyde 3-phosphate dehydrogenase (GAPDH) gene.

\section{Immunohistochemical analysis}

Streptavidin biotin peroxidase immunohistochemical staining method was applied to show the immune expression of Gas6 protein and Axl, Sky receptors proteins in paraffin-embedded tissues. The immune expression positivity in BC tissue was observed as cytoplasmic staining. According to the intensity of staining, it was scored as 0 (Figure 1A) +1 (Figure 1b) +2 (Figure 1c),+3 (Figure 1d). Immunohistochemistry expression index was obtained by multiplying the cytoplasmic staining density and the ratio of stained cells. Two authors, who were blinded to the clinical course of the patients, independently evaluated immunoreactivity, and the average counted by these two authors was used for statistical analyses.

\section{ELISA method}

The human GAS6 sandwich ELISA development kit (RED Systems, Inc., Minneapolis, MN, USA) and a Substrate Reagent Pack (Color reagent A\&B) (RED Systems, Inc.) were used to measure plasma GAS6 levels. Our group has been optimized the development kit to measure human plasma GAS6 levels and established reference intervals (10). Briefly, the following parameters were tested for optimization: type of antibody; capture antibody concentration; dilution solution; dilution ratio of samples and calibrators; blocking agent (BSA or nonfat dry milk), and incubation time and temperature. Dilution solution for samples and calibrators was PBST containing $1 \mathrm{mM}$ EDTA and 1\% BSA. Dilution ratio of samples and calibrators was $1 / 40$. Incubation time during antigen antibody interaction (both capture and detection antibodies) was $1 \mathrm{~h}$ at $37^{\circ} \mathrm{C}$. After analytical validation studies of the method, samples were analyzed. 


\section{Statistical analysis}

In descriptive statistics of the data, frequency, ratio, mean and standard deviation values were used.

The distribution of data was tested with KolmogorovSmirnov. Student t test and ANOVA were used to analyze the parametric section data. Mann-Whitney $U$ and Kruskal-Wallis tests were used for the analysis of nonparametric data. SPSS 15.0 software (SPSS, USA) was used in the analysis.

\section{RESULTS}

\section{Patient demographics}

The BC patients were grouped according to their pathological degrees and stages: Ta low grade $(\mathrm{n}=16)$, Ta high grade $(\mathrm{n}=5)$, T1 low grade $(\mathrm{n}=10)$, T1 high grade $(\mathrm{n}=10)$, T2 high grade $(\mathrm{n}=14)$ and normal bladder mucosa control group $(n=12)$. Mean ages of the patients with $B C$ and the control group were $62.8 \pm 10.7$ and $57.3 \pm 7.0$ years, respectively $(\mathrm{p}>0.05)$. Patients with $B C$, were male in $81.8 \%$ and female in $18.2 \%$, while the control group consisted of male patients.

\section{Tissue analyses}

The qPCR results showed that the mRNA expression of Gas6 and Axl receptor were higher in the tumor-positive patient group, where Sky receptor gene were higher in control group, these differences were not significant $(p>0.05)$ (Table 1$)$. When the patients are grouped according to the grade and stage, significant differences were observed for Gas6 and Axl receptor genes $(p<0.05)$. But no significant difference was found for Sky receptor ( $>0.05$ ) by qPCR (Figure 2 ).

Table 1.

Gas6, Axl, Sky receptor gene expression copy level assessed by the QPCR method.

\begin{tabular}{|l|cccc|cccc|c|}
\hline & \multicolumn{4}{|c|}{ Control group } & \multicolumn{3}{c|}{ Tumor-positive patient group } & p \\
& $\mathbf{n}$ & Median & Min. & Max. & $\mathbf{n}$ & Median & Min. & Max. & \\
\hline Gas6 & 11 & 60.6 & 7 & 294 & 50 & 73.1 & 10 & 1810 & $0.223^{*}$ \\
Axl & 12 & 288.7 & 145 & 578 & 55 & 421.5 & 87 & 1997 & $0.288^{*}$ \\
Sky & 11 & 10000 & 2888 & 15497 & 54 & 8048 & 1591 & 31333 & $0.588^{*}$ \\
\hline${ }^{*}$ Mann Whitney Utest.
\end{tabular}

Figure 2.

Expression of Gas6 and Axl receptor mRNAs in BC against tumor stage and grade by qPCR.

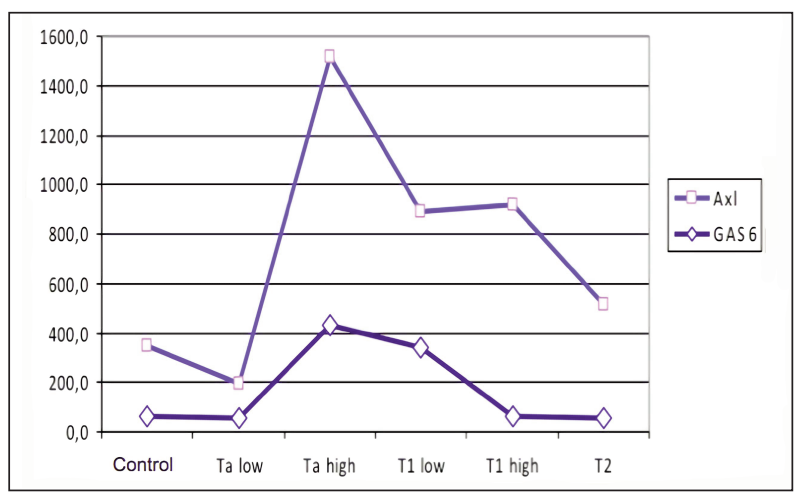

Table 2.

Immunohistochemical expression index of Gas6 protein, Axl, Sky receptors for $B C$ and control group.

\begin{tabular}{|l|cccc|cccc|c|}
\hline & \multicolumn{4}{|c|}{ Control group } & \multicolumn{3}{c|}{ Tumor-positive patient group } & p \\
& n & Median & Min. & Max. & n & Median & Min. & Max. & \\
\hline Gas6 & 6 & 5 & 0 & 90 & 32 & 85 & 0 & 300 & 0.006 \\
Axl & 6 & 15 & 0 & 70 & 28 & 60 & 10 & 200 & 0.037 \\
Sky & 6 & 50 & 0 & 200 & 32 & 180 & 0 & 300 & 0.261 \\
\hline
\end{tabular}

Figure 3.

Gas6 protein levels in plasma samples according to the stage and the grade of the BC patients with ELISA analysis.

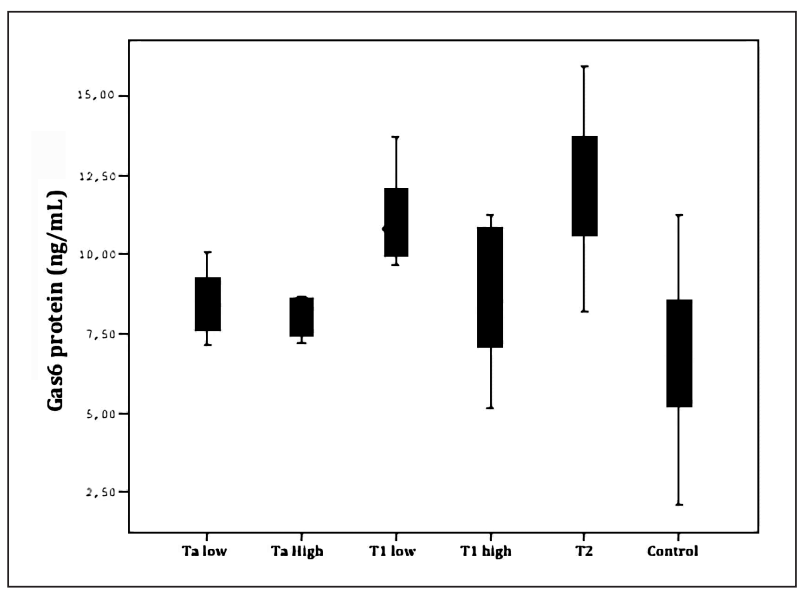

The immunohistochemical expression index for the Gas6 and Axl receptor were statistically higher compared to the control group $(\mathrm{p}<0.05)$. The immunohistochemical expression index of Gas6 protein, Axl, Sky receptors for $\mathrm{BC}$ and control group is shown in Table 2.

\section{Plasma and urine analyses}

The mean plasma Gas6 protein levels for the control group and the BC patient group were $6.5 \pm 2.6 \mathrm{ng} / \mathrm{mL}$ and $9.9 \pm 2.4 \mathrm{ng} / \mathrm{mL}$, respectively ( $<<0.001)$. The distribution according to the stage and the grade of the patients are shown in Figure 3. Gas6 protein was not detected in urine samples by ELISA.

\section{Discussion}

In the present study, an association between BC and expression of Gas6, Axl and Sky was identified using three different methods: qPCR and immunohistochemistry in tissues and Gas6 levels in plasma by ELISA.

The qPCR analysis showed that mRNA expression of Gas6 and Axl are higher in the BC group than the control group but not significantly $(p>0.05)$. mRNAs of Gas6 and Axl was higher in Ta high grade and T1 low grade significantly, but gradually decreasing in $\mathrm{Tl}$ high grade and T2 stages. Using the immunohistochemical examination, the $\mathrm{BC}$ group showed significantly higher $(\mathrm{p}<0.05)$ Gas6 and Axl receptor expression compared to the control group. ELISA analysis showed higher Gas6 protein levels in plasma of the $\mathrm{BC}$ group compared to the control group ( $\mathrm{p}=0.001)$, where highest levels are detected in patients with $\mathrm{T} 2$ tumors. 
The definitive diagnosis of $\mathrm{BC}$ ultimately depends on cystoscopic examination of the bladder, which is an invasive method. There are continuous efforts for the development of non-invasive reliable tumor markers to facilitate the diagnosis. However, none of these markers have been accepted for the diagnosis or follow-up in routine practice (11). By the help of further studies, the Gas6/Axl axis may represent an attractive diagnostic tool for BC. Relationship between various physiological events and Gas6, and/or its receptors has been demonstrated, however, its exact mechanism has not been elucidated yet $(12,13)$. The relationship between Gas6 and/or its receptors with tumor suppressor genes such as Inositol polyphosphate-4-phosphatase (INPP4B) remains uncertain (14). The Gas6 gene and particularly the Axl receptor are highly overexpressed in many diseases. Numerous biological dysfunctions, inflammatory diseases and autoimmune disorders are related to the overexpression of Gas6 and its receptors (6). They also participate in the development, progression and metastatization of a range of malignancies (15). Prostate cancer, breast cancer, lung cancer, leukaemia and cancers of gastrointestinal tract including colon are the most studied malignancies $(5,6,16)$. Recent studies have also demonstrated an important role of AXL signaling in tumor proliferation, survival, stem cell phenotype, prognosis, metastasis, and resistance to cancer therapy (16). However, there is an opposite situation in renal cell carcinoma, which is a urogenital tumor where the Gas6 and Axl-Sky receptors are associated with good prognosis (17). When we look at the stage and grade of BC, it seems that mRNAs of Gas6 and Axl receptor are very close to each other in the control and Ta low grade group.

The malignant potential of low-grade $\mathrm{BC}$, that was formerly regarded as 'low malignant potential papillary urothelial neoplasia', may be related to different molecular pathological and histopathological features. In this respect, it is similar to the new WHO-ISUP classification (18). In the present study, the expression of Gas6 was higher at Ta high grade and Tl low grade, but differentiation was gradually decreasing at $\mathrm{T} 1$ high grade and $\mathrm{T} 2$ stages. Similarly, in the study of Sun et al., the gene expression of Gas6 and Axl receptor was found to be higher in Gl endometrial cancer, however, it was gradually decreasing in G2 and G3 endometrial cancers where the differentiation is poor (19).

Using the immunohistochemical examination, Gas6 and Axl receptor were found to have a significantly higher protein expression at $\mathrm{BC}$ compared to the control group. However, similarly to Sky receptor qPCR results, there was no statistically significant difference between the BC and the control group. Using immunohistochemistry examination, Hattori et al. investigated the relationship between increased expression of the Axl/Gas6 signal cascade and prognosis of patients with upper tract urothelial carcinoma. They concluded that the protein expression of Axl and its ligand Gas6 is related to worse clinical outcome in upper tract urothelial tumors (20).

The plasma levels of Gas6 protein measured by ELISA were significantly higher in the $\mathrm{BC}$ group compared to the control group. In addition, mean levels of Gas6 protein in plasma were significantly higher in T2 patients compared to other groups. This may be important for the separation of the muscle invasive $\mathrm{BC}$ from non-muscle invasive $\mathrm{BC}$. Therapeutic potential of AXL inhibition has been explored for cancer therapy (21). A variety of AXL inhibitors have been developed and are efficacious in preclinical studies. These agents offer new opportunities for therapeutic intervention in the prevention and treatment of advanced disease. For the treatment of the breast cancers, BGB324 (R428) and SGI7079, which are the highly selective Axl tyrosine kinase inhibitors, entered in clinical studies $(22,23)$. Mao et al. showed that GAS6 was overexpressed in $\mathrm{BC}$ cells. They also found that high levels of GAS6 expression were related to tumor stage, grade, and poor overall survival (24). Unfortunately, there are no enough clinical studies on anti-Axl/Gas6 therapy focusing on BC. However, in light of the future studies, this pathway could be a candidate as novel biomarker and as an approach for treatment for BC.

\section{Limitations of the study}

This hypothesis-generating study and our results have some limitations such as small sample size. The control group consists of the normal bladder tissues of the prostate cancer patients is another limitation of the study. Normal bladder tissue is excised as a standard surgical procedure during radical prostatectomy operations. We preferred to use this normal bladder tissue as a control group without an ethical restriction. We could not excise the normal bladder tissue from healthy individuals as a control group because of the ethical problems. Gas6 and its ligands might represent an attractive diagnostic tool in the future. However, expression of these proteins was studied in tissues requiring an invasive biopsy to be obtained. On the other hand, plasma Gas6 ELISA results were also promising for $\mathrm{BC}$ diagnosis and could be used as non-invasive diagnostic test. Of course, future studies with larger sample size will provide more reliable information for implementation of plasma Gas6 test as a biomarker. ELISA method was used to detect the urine Gas6 protein levels but Gas6 protein was not detected in urine samples. The sensitivity of this method may not be appropriate for determining the level of Gas6 protein in urine samples. Gas6 protein could make a complex with soluble form of Axl (25). Further studies for optimization of plasma Gas6 ELISA method for measurement of Gas6 in urine samples are necessary.

\section{Conclusions}

We evaluated the relationship between Gas6/RTKs and $\mathrm{BC}$ with three different methods by performing qPCR analysis, immunohistochemistry and ELISA analysis. Our findings indicate that mRNAs of Gas6 and Axl receptor are closely related to tumor stage and grade in patients with BC. Further studies are needed for understanding the role of Gas6 and its TAM receptors on the neoplastic transformation in terms of novel biomarkers and potential therapeutic targets.

\section{ACKNOWLEDGMENTS}

This study was supported by Marmara University Scientific Research Projects Committee (Grant number: SAG-C-TUP130612-0208). 


\section{References}

1. Antoni S, Ferlay J, Soerjomataram I, et al. Bladder cancer incidence and mortality: A global overview and recent trends. Eur Urol. 2017; 71:96.

2. Kates M, Bivalacqua TJ. Non-muscle invasive bladder cancer. Campell-Walsh Urology 12th edition Elsevier Saunders Press 2020; 135:14115.

3. Robinson DR, Wu YM, Lin SF. The protein tyrosine kinase family of the human genome. Oncogene 2000; 19:5548-57.

4. Hafizi S, Dahlbäck B. Gas6 and protein S. The FEBS Journal. 2006; 273:5231 44.

5. Brown M, Black JR, Sharma R, et al. Gene of the month:Axl. J Clin Path. 2016; 69:391.

6. Paccez JD, Vogelsang M, Parker MI, et al. The receptor tyrosine kinase Axl in cancer: biological functions and therapeutic implications. Int J Cancer. 2014; 134:1024.

7. Wu G, Ma Z, Cheng Y, et al. Targeting Gas6 / TAM in cancer cells and tumor microenvironment. Mol Cancer. 2018; 17:20.

8. Yeh CY, Shin SM, Yeh HH, et al. Transcriptional activation of the Axl and PDGFR- $\alpha$ by c-Met through a ras-and Src-independent mechanism in human bladder cancer. BMC cancer. 2011; 11:139.

9. Rui X, Wang L, Pan $H$, et al. Lnc RNA GAS6-AS 2 promotes bladder cancer proliferation and metastasis via GAS6-AS 2/miR298/CDK 9 axis. J Cell Mol Med. 2019; 23:865-876.

10. Cagman Z, Bingol Ozakpinar O, Cirakli Z, et al. Reference intervals for growth arrest-specific 6 protein in adults. Scand J Clin Lab Invest. 2017;77:109-114.

11. Babjuk M, Burger M, Comperat E, et al. European Association of Urology on non muscle invasive bladder cancer. EAU Guidelines. 2020; 4:8.

12. Eksi Alp E, Altinkaya N, Cagman Z, et al. Plasma growth arrest-specific 6 levels in term and preterm newborns. J Mat-Fet Neo Med. 2018; 31:1151.

13. Uras F, Küçük B, Özakpınar ÖB, et al. Growth Arrest-Specific 6 (Gas6) and TAM receptors in mouse platelets. Turk J Hemat. 2015; 32:58.

14. Lopez SM, Hodgson MC, Packianathan C, et al. Determinants of the tumor suppressor INPP4B protein and lipid phosphatase activities. Bioch Biophy Res Comm. 2013; 440:277.

15. Zhang S, Xu XS, Yang JX, et al. The prognostic role of Gas6 / Axl axis in solid malignancies: a meta-analysis and literature review. Oncotargets and Therapy. 2018; 11:509.

16. Rankin E, Giaccia A. The receptor tyrosine kinase AXL in cancer progression. Cancers. 2016; 8:103.

17. Gustafsson A, Martuszewska D, Johansson M, et al. Differential expression of Axl and Gas6 in renal cell carcinoma reflecting tumor advancement and survival. Clin Cancer Res. 2009; 15:4742.

18. Sauter G, Algaba F, Amin M, et al. Tumors of the urinary system: non-invasive urothelial neoplasias. In: Eble JN, Sauter G, Epstein Jl, Sesterhenn I, eds. WHO classification of classification of tumors of the urinary system and male genital organs. Lyon: IARCC Press 2004; 29 .

19. Sun WS, Fujimoto J, Tamaya T. Coexpression of growth arrestspecific gene 6 and receptor tyrosine kinases Axl and Sky in human uterine endometrial cancers. Ann of Onco. 2003; 14:898.

20. Hattori S, Kikuchi E, Kosaka T, et al. Relationship between increased expression of the Axl/Gas6 signal cascade and prognosis of patients with upper tract urothelial carcinoma. Ann Surg Oncol. 2016; 23:663.

21. Wu X, Liu X, Koul S, et al. AXL kinase as a novel target for cancer therapy. Oncotarget. 2014; 5:9546.

22. Holland SJ, Pan A, Franci C, et al. R428, a selective small molecule inhibitor of Axl kinase, blocks tumor spread and prolongs survival in models of metastatic breast cancer. Canc Res. 2010; 70:1544.

23. Wang X, Saso H, Iwamoto T, et al. TIG1 promotes the development and progression of inflammatory breast cancer through activation of Axl kinase. Cancer Res. 2013; 73:6516.

24. Mao S, Wu Y, Wang R, et al. Overexpression of GAS6 promotes cell proliferation and invasion in bladder cancer by activation of the PI3K/AKT pathway. Onco Targets Ther. 2020; 13:4813-24.

25. Ekman C, Stenhoff J, Dahlback B. Gas6 is complexed to the soluble tyrosine kinase receptor Axl in human blood. J Thromb Haemost. 2010; 8:838.

\section{Correspondence}

Murat Akgül MD (Corresponding Author) drmuratakgul@gmail.com - Assistant Professor

Tekirdag Namık Kemal University, Medical School, Urology Department, Süleymanpassa, Tekirdağ, Turkey, 59030

\section{Özgür Baykan, MD}

ozgurbaykan@gmail.com - Associated Professor

Balıkesir University, Biochemistry Laboratory Balıkesir, Turkey, 10020

Zeynep Çağman, $\mathrm{PhD}$

zeynep794@gmail.com - Assistant Professor

Bezmialem University Pharmacy School, Biochemistry Department, Istanbul,Turkey, 34734

Mustafa Özyürek, PhD

mustafaozyurek1@gmail.com - Research Assistant

Marmara University, Medical School, Physiology Department, Maltepe, Istanbul, Turkey, 34854

Illker Tinay, $\mathrm{MD}$

itinay@yahoo.com - Associated Professor

Anadolu Medical Center, Gebze, Kocaeli, Turkey, 41400

Cem Akbal, MD

cakbal@gmail.com - Professor

Acıbadem University, Urology Department, Altunizade-Üsküdar, Istanbul, Turkey, 34660

\section{Fikriye Uras, PhD}

furas@marmara.edu.tr - Professor

Marmara University Pharmacy School, Biochemistry Department, KadıköyIstanbul,Turkey, 34734

Levent Türkeri, MD

levent.turkeri@acibadem.com - Professor

Acıbadem University, Urology Department, Altunizade-Üsküdar, Istanbul, Turkey, 34660 